\title{
FIRE PROTECTION IN RESEARCH, EDUCATION, AND PROFESSIONAL DISCUSSION
}

\author{
By George P. Melrose
}

CVERY month there come to my desk the various Journals of the Profes-

C sional Societies of Foresters, and in them I see what I believe to be a general condition in the Profession of Forestry. It is a negative, rather than a positive condition, and should be corrected. I shall try to outline the condition as I see it and suggest general remedies.

The condition to which I refer is a lack of sufficient scientific and profes. sional attention to the problem of fire protection, and in the journals it shows up in the comparatively small number of articles of a scientific nature devoted to the subject. This lack of sufficient discussion of the subject is, it seems to me, caused by a similar comparative neglect of the subject in Research and Education. In spite of the great accomplishments in practical organization and fire suppression, it seems that fre protection has been given insufficient recognition as a subject of scientific investigation. It is time fuller recognition was given although administrative staffs are probably still loaded to the extent that they will have as much difficulty in helping as in the past.

Before entering into the details of the discussion it might be just as well to make certain statements regarding the writer's intentions and views, and point out several very evident facts which will tend to keep the problem confined and immediately before us.

1. I use the term "Fire Protection" to mean all activities involved in the problem of protecting the forests from fire. It is a term disliked by many, but the most useful I know. It distinguishes the fire phase from those of ento. mology and pathology, which would be included in the term "Forest Protection," while retaining the benefit of brevity.

2. It is not the intention to minimize, in the least, the importance to Forestry of all other lines of research, education and discussion. Undoubtedly we must have research and instruction in the fundamentals of Silviculture, Mensuration, Products, and Management, if our forests are to be properly handled. At present our activities in those lines even are inadequate.

3. In speaking of the lack of discussion in the journals I refer entirely to scientific or professional articles, as distinct from those designed for popular appeal.

4. The great amount of careful work and thought that has been put into the fire protection problem by hundreds of experienced and trained individuals is fully recognized, as also the great strides that have been made in handling the fire protection problem, but experience thus gained has not been made sufficiently available to others and to the rising generations of foresters 
through the means provided. There is not nearly enough professional exchange of experience and information. I believe we would be farther ahead than we are if such discussion was more general.

The very evident facts that bear on this problem may be summarized briefly as follows:

1. Adequate fire protection is the prime requisite of Forestry and will be for many years to come. Without it all planting, silviculture, and management are ultimately useless.

2. Fire protection is of immediate and urgent concern. The size and regularity of annual losses in forest and other property testify to this.

If the above conditions are true, the natural conclusion is that fire protection should have first and paramount attention in any forestry programme. Judging by the bulk of governmental and private forestry organization this is the case. The overwhelming problem with them all is fire protection. Elaborate organizations are maintained and great funds expended in control, with undoubtedly increasing efficiency; but in spite of this it appears that fire protection is not given adequate attention in programmes of research, in plans of education and instruction and in professional or scientific discus. sion.

RESEARCH

A review of the research programmes of various research organizations in Canada has been given in the Forestry Chronicle for the years 1928 and 1929. These programmes show no research projects in fire protection. A large number of projects is being carried, but the one phase of the forestry problem that is of immediate and constant concern and on which the use of the others largely depends, is neglected. It might be pointed out that the reviews mentioned are not entirely accurate because some very comprehensive fire weather research has been carried out in Ontario, Quebec and British Columbia at least.

In the United States some excellent work has been carried out by Show and Kotok in California and by Gisborne in Northern Idaho. These research workers have undertaken fundamental studies in fire protection along advanced lines, pointing the way to methods of bettering the protection effort. Their work is limited and a review of the projects being carried on shows a very disappointing comparison with other subjects under research.

It is difficult to account for this condition. Speculation points to a variety of causes, probably all of which are partly to blame. We might pursue them all to the times of first thought on Scientific Forestry in this country when European practice and training governed foresters and the stress was placed on silviculture and management. This became reflected in the Forest Schools and then in the later generations of foresters. In the meantime the highly 
practical and necessitous work of fire protection had to be carried on, but comparatively little thought has been given to it as subject to scientific study and application.

\section{EDUCATION}

A review of the curricula of Canadian Forest Schools and several of the leading institutions in the United States shows indeed that certain courses of lectures are given on fire protection, but text books, instruction, freld and laboratory facilities are all on a higher plane for the instruction of students in the other branches, while fire protection gets a minor position and minor attention. Is this not putting the cart before the horse? Should not students of Forestry be instructed in the subject of greatest importance, of most immediate need to them, at least in better proportion to the professional use they will make of their knowledge?

It is recognized that the curricula of the forest schools are crowded at present and any increase in the instruction along the lines of protection must be at the expense of other subjects. At the same time it must also be recog. nized that the biggest problem most of the graduates will face, the most immediate use they will get of their ability will most likely be along the lines of protection from fire. This is the fact that we cannot dodge, and should not allow ourselves to neglect. The first problem, the greatest problem and still the most pressing problem is that of protecting the forests. It cannot wait nor be put off. If ever we are to practice silviculture this problem must be solved. Therefore it needs emphasis in the training of the foresters of the future.

The graduate schools seem to be under the influence of this same idea, for no provision is made for graduate work in the subjects pertaining to fire protection. This is more food for thought and probably adjustment especially in view of the need for more research and more scientific application along protection lines and hence men better trained in the fundamentals of fire protection.

Again, looking for reasons for this lack of emphasis on fire protection we can trace the influence of the older training. Probably the needs of industry emphasizing products and engineering has had its influence, while lack of research in fundamentals and absence of a comprehensive text book may take some of the blame.

\section{TECHNICAL JOURNALS}

A review of the technical journals shows a condition similar to those outlined concerning research and education. In the 10 years from 1919 to 1929 there were only 40 articles, an average of 4 per year, that could be classified as technical discussion of the fire protection problem in the Journal of For 
estry. The Canadian Forestry Chronicle shows only 9 articles in five years. Whether or not the condition evidenced in the journals is the result of the other conditions would be a most difficult proposition to solve, but I am inclined to believe that all three are bound up in it together. However this may be we are apparently very loath to discuss fire protection professionally or scientificially, for compared to other Forestry subjects, discussion on fire protection is very conspicuous by its scarcity.

Great quantities of excellent material is published that can be classified as propaganda. It is designed either as ammunition for the forces of education or for direct reading by the people to be reached. It has resulted in a public attitude of mind that is infinitely better informed than it was a decade ago. This is as it should be, since the public must not only be made conscious of its responsibility, individually and collectively, but must be informed on all the angles necessary to an enlightened electorate.

But in spite of this we find that the technical journals do not devote space to scientific fire protection in proportion to the immediate interest and usefulness of such material. This is not the fault of the journals but of the members of the profession who should be in a position to carry on the discussions and write up the scientific findings.

\section{REMEDIES}

What has gone before is in the nature of criticism of present conditions. Some attempt at a solution of the difficulties in the situations criticised will be suggested with the expectation that others will undoubtedly be able to add materially to them.

If, then, my premises are correct, and, of course, all may not agree, we have to contend with a lack of attention being paid to Fire Protection in Research, Education, and Open Discussion, both intrinsically and comparatively with other angles of the Forest problem. The remedy is, simply, to give Fire Protection more attention.

\section{RESEARCH}

Estimates have varied as to the percentage Fire Protection is of the whole problem of Forestry. Some say as high as $75 \%$ and others even $90 \%$, but certainly it is a very large, compelling and absolutely essential portion. Methods of fighting fires are still very largely "in the war club stage." Many advances have been made in the use of mechanical appliances, a few excellent studies have been instituted in the relationship of weather factors to fires and some small beginnings are shown in organization studies and in the economics of the fire problem, but compared to the importance of the job as commonly measured, the research effort is not enough.

Administrative organizations and individuals within them learn certain 
fundamentals by the long and effort wasting methods of experience, of trial and error. Some of this experience gets passed on within the organization as a whole, and a very little between organizations, but men absorbed in the active business of running an intensely busy organization and fighting fires have not the time, and frequently not the means either, to record and pass on their experience, or to undertake properly organized research on any subject. Neither can general experience be taken as a guide to the fundamentals of the question, since it is invariably bound up with the prejudices and weaknesses of the individual.

The research method of getting at the fundamental and subsequent facts is the only economic way. It is urgently needed in greater volume to-day, and for many years to come if we are ever to get away from depending for fire protection on the man with all his width between his shoulders instead of between his ears. Advance in the suppression of fires, as in any other line of forest activity must be made with the aid of science.

Research organizations must then, expand their work on fire protection. As mentioned before some small amount of work has been done in Canada on Weather in it's relation to fires. A very small beginning has been made on Lightning storms and their characteristics and effects. In the United States excellent work has been done in the North West and Pacific Coast on weather factors, some on fire behavior and some on organization, but even there the amount of work has not been commensurate with the importance of the problem. No one has taken up adequately, or at all, the questions of fire behavior under varying conditions of weather, cover and topography. The conception of "Inflammability types" rather than "Forest types," as the controlling divisions in fire protection has received no attention in research and yet is a most fundamental factor in the protection problem. The "Hour Control," problem of organization is just becoming understood but requires greatly increased research in its fundamental factors and its application before becoming of practical use to the protection organizations.

These are only a few suggestions as to lines of research that are fundamental to the protection problem. Some have been given a little attention and some neglected, but all need to be greatly expanded. In addition research needs to be started, or expanded where some small beginnings may have been made in economics of fire protection, including the adequacy of present effort and expenditures; the use of new and mechanical equipment; the use of chemicals as extinguishers and deterrents; the improvement of radio communication in the woods; and the use of aeroplanes and other modern machinery in the detection and suppression of fires.

How to accomplish an expansion in the forest fire research programme is a difficult problem. There is no doubt that total appropriations for research 
are, at the present time, inadequate, but until greater funds are available, there are only two methods of increasing along fire lines, viz:-(a) Put more time and effort on fire at the expense of the other subjects. (b) Encourage more studies under research principles among administrative organizations.

I believe that more research effort placed on the fire protection problem would result in greater and more immediate benefit than on many of the projects being carried forward at present. It is undoubtedly true that we must understand the fundamentals of reproduction, growth, and utilization of our forests before we can manage them according to forestry principles, but it is also undoubtedly true that we must solve the fire problem first.

\section{EDUCATION}

Fire protection should be a science. The fundamental factors involved are subject to scientific study and solution. If any great advances are to be made in the protection of our forests from fire they must be based on adequate study and research. That means that trained men are required.

At the same time the organization of fire protection facilities, the ad. ministrative study and operation of fire plans and even the preliminaries of fre prevention call for as complete a knowledge as possible of all the factors involved in and underlying those activities.

The young foresters entering their profession have not, I believe, received sufficient grounding in the fundamentals of fire protection. Compared to the other lines of forestry education, the time placed on fire protection is not adequate, and especially in view of the immediate and practical use to which most graduates could put such training.

With curricula already crowded it is hard to see where more time could be put on protection without letting other important subjects slide, but some such action should be taken, in order to balance up the forestry courses to a better proportion between fire protection and the others.

Special courses are given at various forest schools in such subjects as Logging Engineering, Products, and Utilization. Fire protection is of greater immediate importance to the profession, while the lack of men trained fundamentally in its science is holding back legitimate advance and accounts for many of the errors made in fire organizations. Therefore some attempt should be made at as early a date as possible to institute special courses in fire protection at the Forest schools.

Such special courses could only be started and maintained if graduates could be assured of employment. It is my opinion that most organizations to-day and for some time to come would be better satisfied and better served if the young forest graduates knew more of the fundamentals and practice of fire protection than they do at present. There should be less difficulty in 
placing graduates who have specialed in fire protection than in some of the other lines given special attention.

As time advances it becomes more evident that forest school graduates must soon enter forest organizations, especially the Government Services, as rangers or assistant rangers. Here their most important work will be fire protection, and all the preliminary training they can get will stand them in good stead, while their opportunity to practice silviculture or management is likely to be small for some time. Special courses in fire protection will serve this class and their employers to the greatest extent and would lay the foundation for fire protection organizations of the utmost efficiency in every line. The other subjects taught at present would not, of course, be entirely cut out, any more than they are at present in the other special courses, but fire protection subjects would be broadened and enlarged.

Some difficulty is probably experienced at the present time in teaching fire protection through the lack of a thoroughly comprehensive and up-to-date text book. Present knowledge of fire protection practices is contained in a few scattered bulletins and articles, and in the experience of many individuals. It needs to be gathered together and given proper treatment in a text book, or even more than one book. This needs to be taken in hand at once by a competent man who should have the time to gather all the necessary data and to write it in acceptable form. The leaders of the profession or the societies of foresters should institute action in securing the man and the fellowship or subsidy necessary to allow him the time to do the work. With such a text book, ample discussion of fire protection in technical journals and the published results of an adequate research programme it would be possible to give a comprehensive special course in fre protection.

A further educational step that should be taken in fire protection is the short course for rangers. With special courses or expanded facilities in the forest schools for this subject such short courses would be possible. They are certainly desirable, in view of the time it takese the average ranger at present to secure any scientific grounding in the work he is called upon to perform from the time he starts work. Failures in fire protection are very many times due to lack of fundamental knowledge and training. Such could be imparted in a short course to the advantage of the men concerned and the organizations that employ them.

Education must go hand in hand with research and the forest schools must be in close touch with the research organizations. The fundamentals of fire protection research need to be taught as well as of organization and suppres. sion. If research in fire protection is expanded, room will be made for graduates and undergraduates who have specialed, or are specialing, in fire pro- 
tection. The combination will be mutually advantageous to the acceleration of the solution of our greatest problem in forestry.

\section{TECHNICAL JOURNAIS}

The technical journals of the various professional societies do not, by any means give a measure of the time and thought placed on fire protection within the Profession of Forestry. The practical business of fire prevention, suppression, and control has received, and is receiving, thorough and competent thought by administrative foresters. The great successes achieved are a measure of the ability displayed, but the Journals are, I believe, a measure of the scientific work being done in the solution of the many problems faced by the administrative officers.

Without more research work being conducted, little more of published results can be expected in the journals, but there are many fundamental conceptions needing discussion. Practicing foresters, educators and research workers must get together on these conceptions to iron out differences, let others know how far thought has advanced on them, and build up a record of that thought for reference, reflection, and inspiration.

Such fundamental questions as the following need discussion, clarification, and exposition:

(a) The adequacy of present fire protection efforts from economic and operative standpoints, with methods of determining or defining adequacy.

(b) Methods of attaining adequacy where such has not been reached.

(c) Comparison of "Inflammability types" with "Forest types" on which to base suppression effort.

(d) Definition and description of inflammability types for different regions.

(e) Application of Hour control to the fire protection problem, and the fundamentals of organization based on the study.

(f) Theories and methods involved in fire history studies from the standpoints of causes, locality, occurrence, periodic occurrence, tactics, cost and damage.

Furthermore, with the great amount of work being done in fire protection there should be more records of actual organization practices and their basic problems; of suppression tactics; of methods of damage appraisal; of personnel training; and of the use of new or improved equipment. These are matters of common concern. Their discussion or exposition by the foresters using them would not only help all those with similar problems, but would indicate the lines along which further practice and research should follow while stimulating constructive thought in the profession as a whole.

This is the function of a professional journal. The forestry journals are 
doing their part with the exception, as I have pointed out, that fire protection is not taking the space in proportion to its importance and immediate utility.

\section{SUIMMARY}

A condition seen in the professional forestry journals of lack of attention to the important branch of fire protection led to inquiry into the amount of attention given it in Research and Education. The result showed that the journals indicate more or less the proportionate attention given fire protection in those branches of the profession.

The obvious remedies are suggested of increasing the attention given fire protection in Research, Education and in the professional journals, even at the expense of other branches of forestry that, although ultimately necessary to its full and proper practice, are not as immediately appliable to urgent administrative problems.

Suggestions are given for the lines along which Research, Education and Discussion should be increased to bring fire protection in line with other branches, and lay the proper fundamental base for its scientific practice.

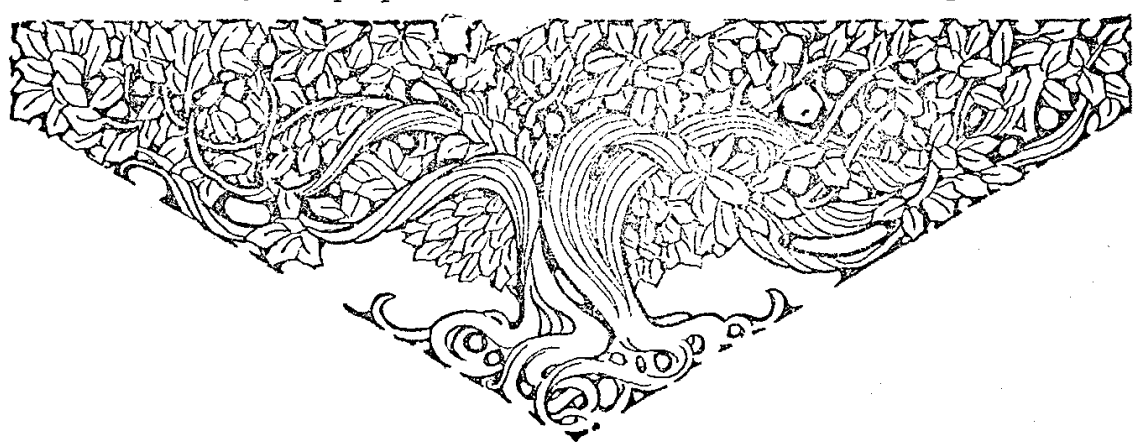

